\title{
UNPALATABILITY OF THE PYRROLIZIDINE ALKALOID- CONTAINING MOTH UTETHEISA ORNATRIX, AND ITS LARVA, TO WOLF SPIDERS ${ }^{1}$
}

\author{
By Thomas EISNer AND MARIA EISNER
}

\section{INTRODUCTION}

The moth Utetheisa ornatrix (family Arctiidae) derives protection from pyrrolizidine alkaloids. It sequesters the toxins from its larval foodplant, retains them into adulthood, and allocates a fraction to the eggs (Eisner and Meinwald 1987, Dussourd et al. 1988). Evidence has shown adults and eggs to be unpalatable to predators. Adults are set free by orb weaving spiders, which cut them from the webs (Eisner 1982, Eisner and Meinwald 1987), and eggs are rejected by coccinellid beetles (Dussourd et al. 1988). Adults and eggs from a laboratory culture free of pyrrolizidine alkaloid are accepted by these predators.

We here report experiments demonstrating that Utetheisa, as larvae and adults, are protected against wolf spiders. Our tests were done with Lycosa ceratiola in Florida, both in the laboratory and field, and made use of Utetheisa adults and larvae of three types: (a) laboratory-raised, alkaloid-containing; (b) laboratoryraised, alkaloid-free; and (c) field-collected.

\section{Materials AND MethodS}

The spider tested, Lycosa ceratiola, is relatively abundant at night on the sandy fire lanes at the Archbold Biological Station, Lake Placid, Florida. We spotted them with head-lamps by their strong reflected eye shine (Kaston 1978).

For laboratory testing, spiders were taken into vials and transferred singly into plastic containers $(17 \mathrm{~cm}$ diameter, $11 \mathrm{~cm}$ height; with shallow bottom layer of sand), within which they quickly

\footnotetext{
${ }^{1}$ Paper no. 103 of the series Defense Mechanisms of Arthropods; no. 102 is Bogner and Eisner, Experientia (submitted). Corresponding author: Thomas Eisner, Cornell University, Neurobiology \& Behavior, W347 Mudd Hall, Ithaca, NY 14853-2702. Manuscript received by the editor March 22, 1991.
} 
assumed normal quiescent stances. They were usually tested on the night of capture, or at the latest 3 days thereafter. Prior to testing they were given only water (cotton-plugged vial). Presentation of test items involved taking an Utetheisa adult or larva in forceps, and dropping it from just above the spider to directly in front of the spider's chelicers.

For field testing, items were drop-delivered in the same fashion, but to recipient spiders that were still in place, naturally positioned on the ground where they had been spotted in the night. Approaching them slowly to within close range while maintaining them in the beam of light could be done usually without startling them.

The Utetheisa from laboratory culture were raised on two types of diet: alkaloid-free diet, from which alkaloid-free Utetheisa were obtained, individuals henceforth referred to by the the prefix (-); and alkaloid-containing diet, from which (+)individuals were obtained. Details about the composition of these diets are given in previous papers (Conner et al. 1981, Dussourd et al. 1988). Suffice it to say that the first diet is based on pinto beans, which are free of pyrrolizidine alkaloid, and the second is supplemented with seeds of Crotalaria spectabilis, a major host plant of Utetheisa. C. spectabilis contains the pyrrolizidine alkaloid monocrotaline. Our (+)individuals could therefore be expected to have substantial systemic loads of this alkaloid. Indeed, analysis had shown (+)adults and midsize (+)larvae to contain, respectively, $630 \pm 50 \mu \mathrm{g}(\mathrm{N}=$ $31)$ and $152 \pm 25 \mu \mathrm{g}(\mathrm{N}=15)$ monocrotaline per individual ( $\overline{\mathrm{x}} \pm$ SEM) (adult data, B. Roach, unpublished; larval data, J. Kopecky, unpublished). We used full-grown, last-instar larvae in our tests, which doubtless contained alkaloid levels higher than those of midsize larvae.

The field-collected Utetheisa [herein designated as (F)Utetheisa] were captured in the environs of Lake Placid, Florida, in and around stands of Crotalaria mucronata, a second major hostplant of the moth. C. mucronata contains usaramine as its pyrrolizidine alkaloid, a compound closely similar to monocrotaline. Utetheisa adults associated with this foodplant are known to contain usaramine in substantial amounts $[\overline{\mathrm{x}}=540 \pm 30$ (SEM) $\mu \mathrm{g}$ usaramine/moth $(\mathrm{N}=31)$; $\mathrm{B}$. Roach, unpublished]. No comparable data are available for larvae from this plant, although the ones we tested were of medium to full size, and thus presumably 
endowed with near equivalents or equivalents of adult usaramine loads. Seven of the ten field-collected larvae were taken from the plants while they were still in what we estimated was the $3^{\text {rd }}$ instar. They were maintained on fresh leaves and seed-pods of $C$. mucronata in the laboratory for several days and not tested until they achieved mature or nearly mature size.

Adult Utetheisa and spiders were sexed, but for the laboratory tests only; larvae were never sexed. Each test involved presentation of one type of prey item to 10 separate spiders. No spiders were tested twice, nor were rejected Utetheisa larvae or adults ever reused. In tests where sexes were noted, moths and spiders were paired in every sex combination. The specifications for the 10 tests, with regard to setting, prey item offered, and (where noted) male/female ratio of item and spider, were as follows:

1. Laboratory: (+)moths (5/5) (spiders 5/5)

2. Field: $(+)$ moths

3. Laboratory: (-)moths (5/5) (spiders 4/6)

4. Field: (-)moths

5. Laboratory: (F)moths (5/5) (spiders 5/5)

6. Laboratory: (+)larvae (spiders 4/6)

7. Field: (+)larvae

8. Laboratory: (-)larvae (spiders 3/7)

9. Field: (-)larvae

10. Laboratory: (F)larvae (spiders 2/8)

\section{RESULTS}

The results, summarized in Figure 1, were clear cut. All alkaloid-containing Utetheisa $[(+)$ larvae and (+)adults from laboratory culture; (F)larvae and (F)adults from the field] were rejected by Lycosa, while (-)controls, devoid of alkaloid, were eaten.

The observed behavior by spiders did not differ in the laboratory and field tests. (-)Larvae and adults were instantly seized by the spiders (Fig. 2), which bore upon them with the chelicers, and kept them in a persistent hold, sometimes literally enfolding them with the legs, until the venom took effect. Laboratory tests were intermittently monitored until completion of feeding. Prey offerings had been made in the evening, and it usually took the spiders overnight to consume the prey. Larvae were reduced to shrivelled 


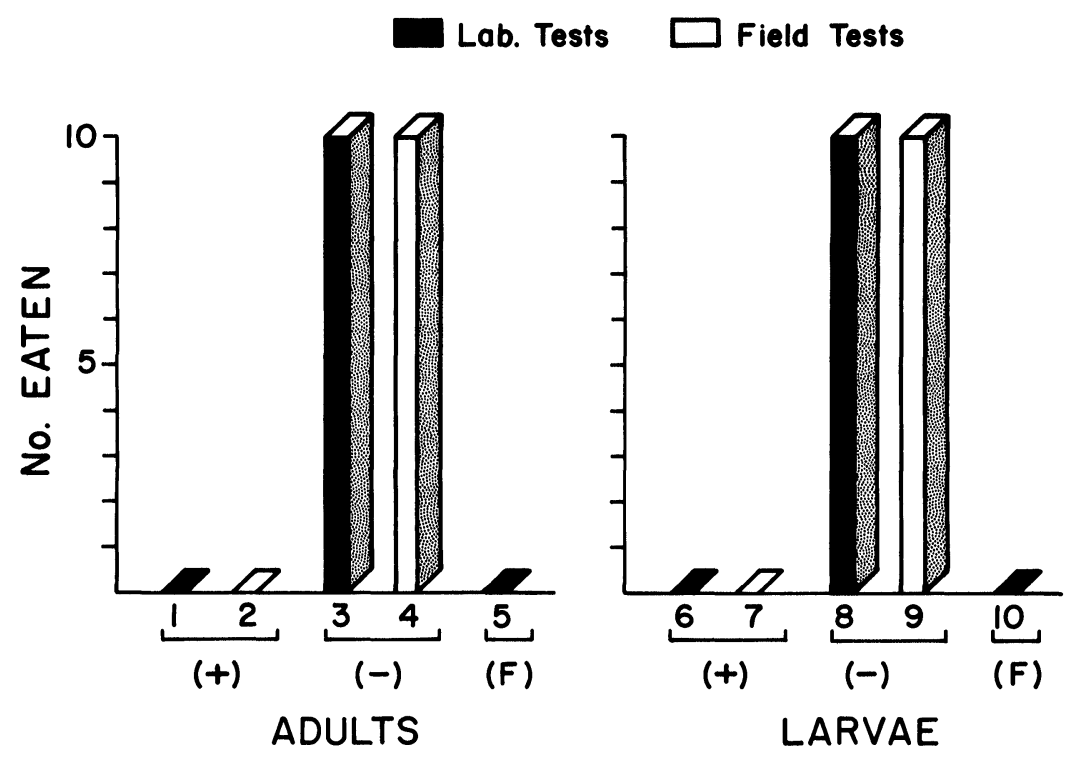

\begin{tabular}{|c|c|c|}
\hline $\begin{array}{c}\text { Test } \\
\text { No. }\end{array}$ & $\begin{array}{c}\text { Rejection Time (sec) } \\
{[\bar{x} \pm \text { SEM (range) }]}\end{array}$ & $\begin{array}{c}\text { Fraction } \\
\text { Survivors }\end{array}$ \\
\hline 1 & $12 \pm 4(1-40)$ & $10 / 10$ \\
\hline 2 & $9 \pm 8(1-80)$ & $10 / 10$ \\
\hline 5 & $9 \pm 3(1-35)$ & $10 / 10$ \\
\hline 6 & $13 \pm 5(1-50)$ & $10 / 10$ \\
\hline 7 & $56 \pm 38(1-390)$ & $8 / 10$ \\
\hline 10 & $48 \pm 23(1-181)$ & $10 / 10$ \\
\hline
\end{tabular}

Figure 1. Acceptability of adults and larvae of Utetheisa ornatrix to the spider Lycosa ceratiola. The Utetheisa were of three types, two of which $[(+),(\mathrm{F})]$ contained pyrrolizidine alkaloid. The tests are numbered on the $\mathrm{x}$-axis, in accord with the listing in the text. Sample size is $N=10$ prey items per test. Further details in text. 


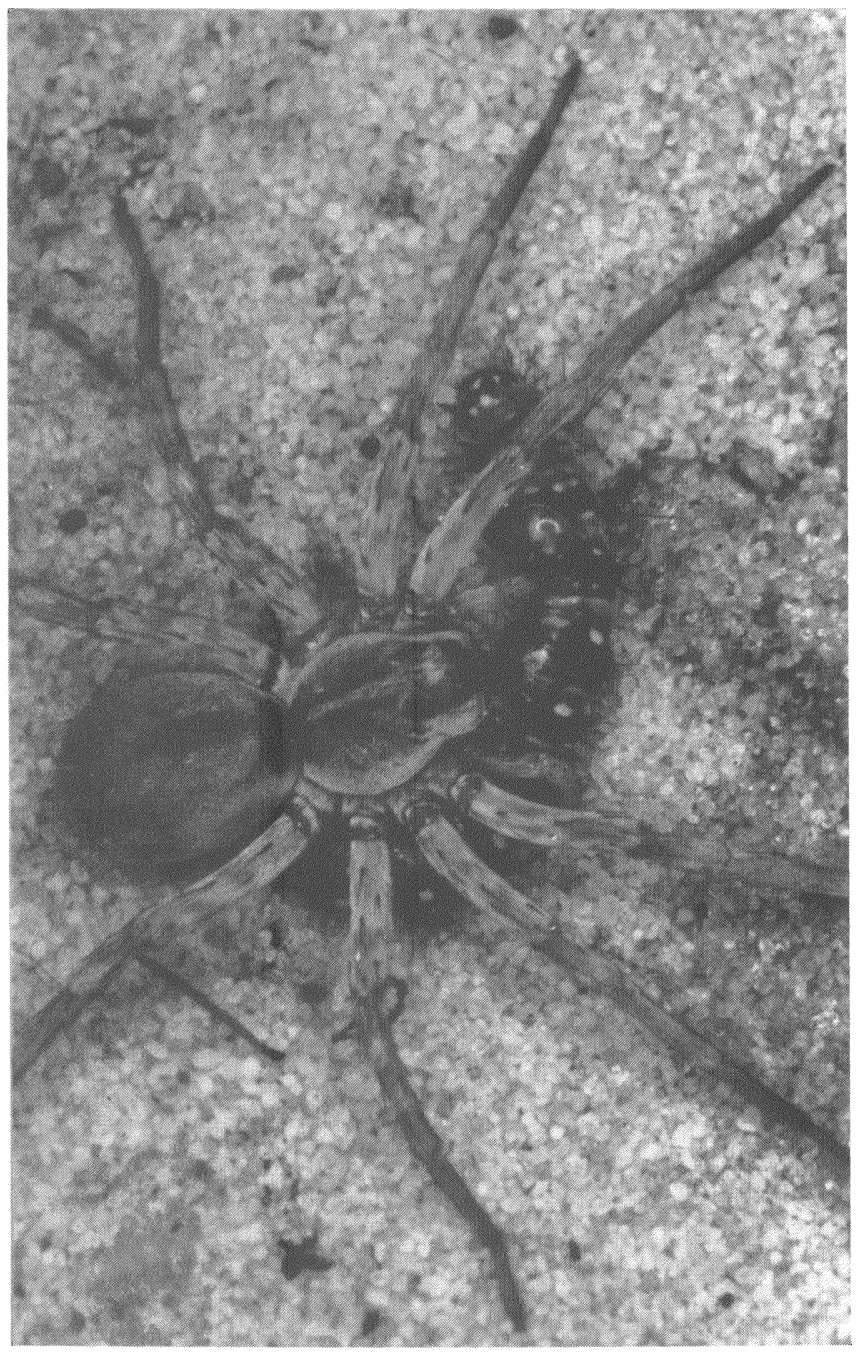


integumental remains, and adults to compacted pellets and detached wings.

The release time for the alkaloid-laden Utetheisa was variable (Fig. 1). Adults almost without exception were freed within the minute of capture. (F)Moths were released as quickly as (+)moths, indicating that wild Utetheisa were as chemically unacceptable to Lycosa as individuals that had acquired their alkaloid from our artificial diet. Adults all survived the encounters uninjured. Many took to the wing instantly upon release. Larvae were not as quickly released, but they too survived the tests in most cases (as was determined by checking them for locomotory impairment after 48 hr). But there were two exceptions. These were both (+)larvae, from field tests, that had been held by spiders for 75 and $390 \mathrm{sec}$ respectively. They were moribund on the second day and dead after $48 \mathrm{hr}$. We speculate that they died from envenomization.

\section{Discussion}

Pyrrolizidine alkaloids, already known to protect Utetheisa against other predators (Eisner 1982, Eisner and Meinwald 1987, Dussourd et al. 1988), evidently protect the insect also against Lycosa ceratiola. Our field-collected Utetheisa proved as unacceptable to the spider as their laboratory-raised counterparts, indicating that the slightly different pyrrolizidine alkaloids they contained, usaramine and monocrotaline, are closely matched in deterrent potency.

Survival was high on the part of rejected individuals. Adult moths survived without exception; larvae survived with only two exceptions. The alkaloid-free controls were all eaten.

It would obviously have been desirable to test directly for the deterrency of pyrrolizidine alkaloids, by adding the chemicals topically to edible items (for instance, mealworms), and seeing whether by doing so one could render such items distasteful to Lycosa. We did such tests in earlier work with the orb-weaving spider Nephila clavipes, and found that pyrrolizidine alkaloids are indeed chemically deterrent (Eisner and Meinwald 1987). We suspect, therefore, that the chemicals would also have proved deterrent to $L$. ceratiola. In fact, pyrrolizidine alkaloids might be deterrent to lycosids generally, and perhaps even to spiders as a group. On numerous occasions, while in Florida, we offered wild- 
caught adult Utetheisa to lycosids in the field (by the same feeding technique used herein) only to find the moths invariably rejected. We doubtless encountered a number of different lycosids by such random testing. Moreover, we have data (albeit scant), that adults of Utetheisa are distasteful also to jumping spiders (Phidippus audax).

Lycosids are probably not major predators of Utetheisa, although they might encounter the insect at times. Lycosids forage primarily on the ground, but - as anyone who searches for the spiders at night by light may note-they do on occasion take up positions on the branchings of vegetation. It is when they venture into such habitat, and specifically onto Crotalaria plants, that they could potentially be a threat to Utetheisa. Of special importance might be the vulnerability of the Utetheisa larva when it crawls away from its hostplant in search of a pupation site (Bogner and Eisner 1991). It is then, when by necessity traversing ground, that it might be most at risk from lycosids.

\section{SUMMARY}

The arctiid moth, Utetheisa ornatrix, sequesters toxic pyrrolizidine alkaloids from its larval foodplants. Evidence is presented indicating that the alkaloids are the basis of unpalatibility of this insect to a lycosid spider (Lycosa ceratiola). Larval and adult Utetheisa endowed with pyrrolizidine alkaloid are rejected by the spider, while controls free of alkaloid are invariably eaten.

\section{ACKNOWLEDGMENTS}

Study supported in part by grant AI02908 from NIH, and Hatch grant NYS 191402. The experiments were done at the Archbold Biological Station, Lake Placid, Florida. We are indebted to the staff of the Station for innumerable kindnesses. All spiders were returned to their sites of capture, as were most field-collected Utetheisa (larvae and adults).

\section{Literature Cited}

BOGNER, F. AND T. EISNER

1991. Chemical basis of pupal cannibalism in a caterpillar (Utetheisa ornatrix). Experientia, submitted. 
Conner, W. E., T. Eisner, R. K. Vander Meer, A. Guerrero, And J. Meinwald

1981. Precopulatory sexual interaction in an arctiid moth (Utetheisa ornatrix): role of a pheromone derived from dietary alkaloids. Behav. Ecol. Sociobiol. 9: 227-235.

Dussourd, D. E., K. UbiK, C. HaRvis, J. Resch, J. Meinwald, AND T. Eisner

1988. Biparental defensive endowment of eggs with acquired plant alkaloid in the moth Utetheisa ornatrix. Proc. Nat. Acad. Sci. 85: 5992-5996.

EISNER, $\mathrm{T}$.

1982. For love of nature: exploration and discovery at biological field stations. BioScience 32: 321-326.

EISNER, T. AND J. MEINWALD

1987. Alkaloid-derived pheromones and sexual selection in Lepidoptera. In, G. D. Prestwich and G. J. Blomquist (eds.), Pheromone Biochemistry, Academic Press, Florida, pp. 251-269.

\section{KASTON, B. J.}

1978. How To Know The Spiders. Wm. C. Brown Co., Philadelphia. 

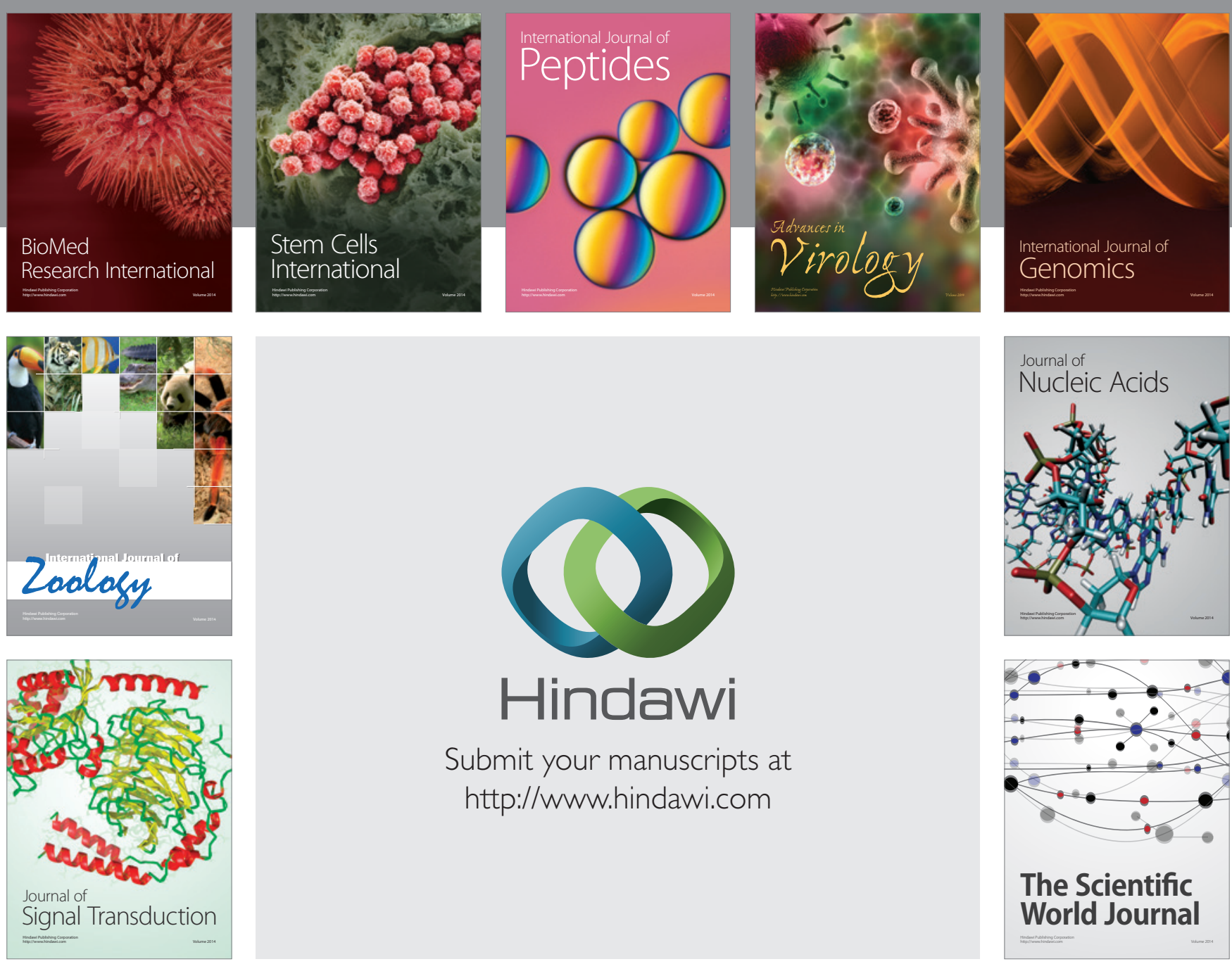

Submit your manuscripts at

http://www.hindawi.com
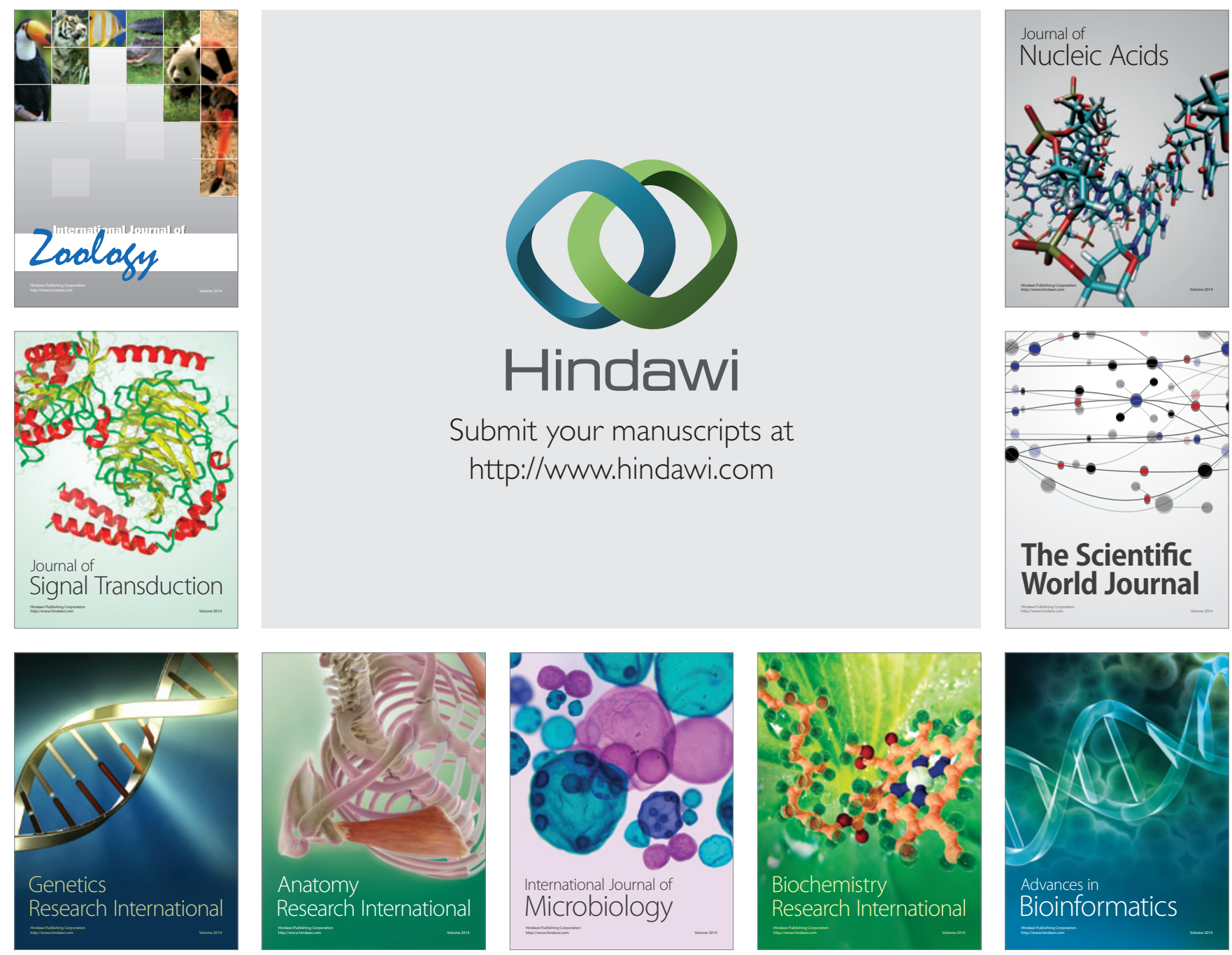

The Scientific World Journal
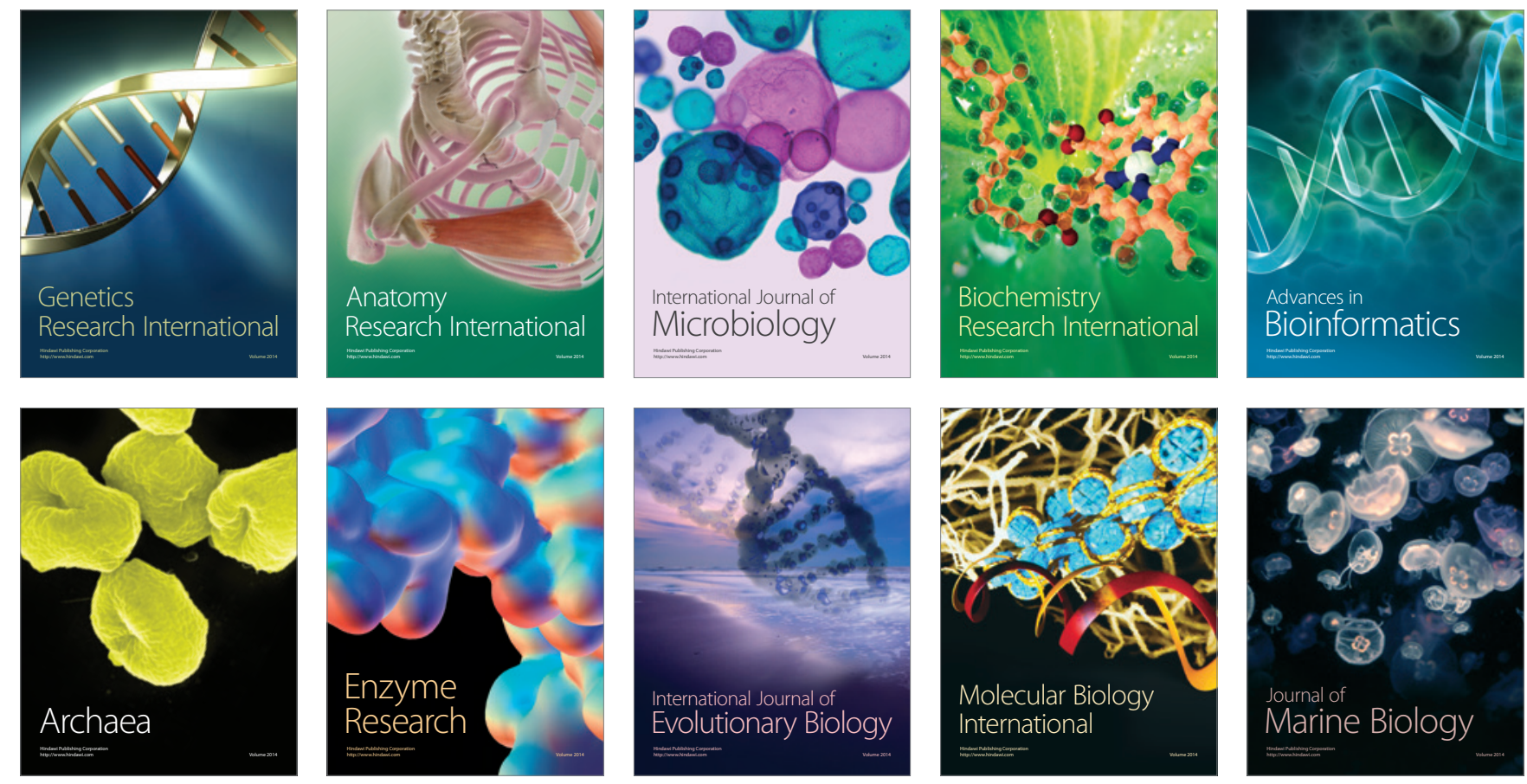